\title{
Development of an Inline Quality Measurement System for Tufting Process
}

\author{
Mesut CETIN, Sven SCHÖFER, Thomas GRIES \\ Institut für Textiltechnik (ITA) of the RWTH Aachen University, Aachen/Germany
}

\begin{abstract}
Missing carbon fibre reinforced plastic production facilities which are fully automated are hindering to the manufacture of large-scale CFRP-components. A two-stage procedure consisting of a preforming process and a resin transfer moulding process is recommended for the manufacturing of composites in large scales. Starting point of the preform process are usually flat textiles structures such as woven or multiaxial. After a pre-cut process they further processed in a sequence of handling, forming, joining and edging to complex, near-netshape textile preform. Afterwards the preform is consolidated via a resin transfer moulding process. Because the preforming process is only partly automatable, high costs arise.
\end{abstract}

Keywords: Carbon, plastic reinforcement, EPS-foam.

\section{INTRODUCTION}

Nowadays the handling and transportation of the preforms impose a significant challenge. Therefor it has to be ensured that the preforms maintain their near-net-shape, their fibre orientation and their compactness throughout all transportation and handling process. To accomplish these criteria a newly developed approach by the Institut für Textiltechnik (ITA) of the RWTH Aachen University is being pursued, in which the preforms are fixated on expanded polystyrene foams (EPS-foams). The fixation on the foam is realized by the tufting technology [1-5] (Figure 1).

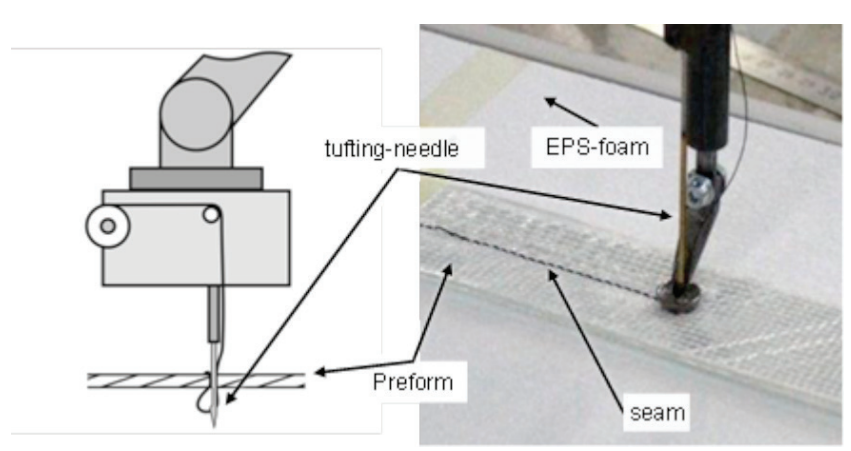

Figure 1. Preform fixation on expanded Polystyrene foams (EPS-foams) by using the Tufting technology (schematic sketch on the left, real process on the right)

The amount of seams depends from the preform weight and the transportation loads. The quality of seams is influenced by yarn material, preform material as well as the properties of the EPS-foam and the geometry of the tufting needle. Process-related seam defects can lead to an unsafe fixation on the EPS-foam. Seam defects can be caused by thread tension which is too high, or an inhomogeneous EPS-foam. Seam defects are leading to fibre disorientation and can damage the preform caused by transportation loads. Therefore the recognition of seam defects during the tufting process is of paramount importance. None of the currently on the market available tufting systems provides a quality management solution which is capable of detecting seam defects in real time. To be able to use the tufting technology for fixation of textile preforms on EPS-foams it is essential to know as much as possible about the seam defects.

The aim is, therefore, to develop an inline quality measurement system which is able to detect seam defects while simultaneously measuring the thread tension in the thread feeding system. This enables to determine the influence of thread tension on the appearance of seam defects. Furthermore the amount of seam defects per seam length can be determined to quantify the remaining load bearing capacity of the seam for the transportation process.

\section{METHODOLOGY}

The detection of seam defects during the tufting process is realised by an optical evaluation of the stitching pattern. Due to the fact that the thread tension affects the quality of 
the seam, a tension sensor is installed in the thread feeding system of the tufting head. A schematic sketch of the quality measurement system is illustrated in Figure 2.

The developed quality measurement system is capable of identifying any tufting seam defects. Table 1 provides an overview of different characteristics which can be detected by the developed system.

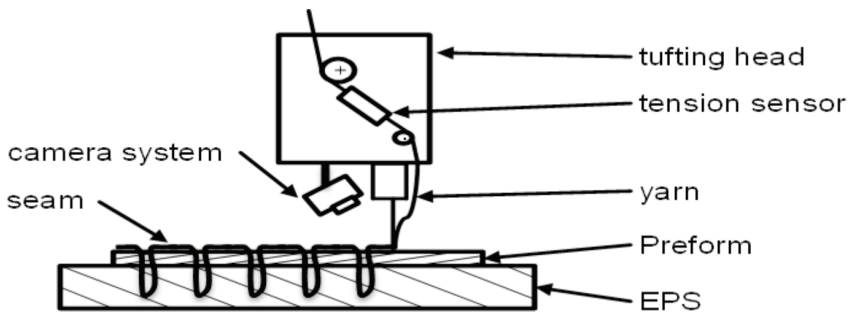

Figure 2. Schematic illustration of the setup for the detection of the seam defects

Table 1. Overview of characteristic seam defects identified by the developed system

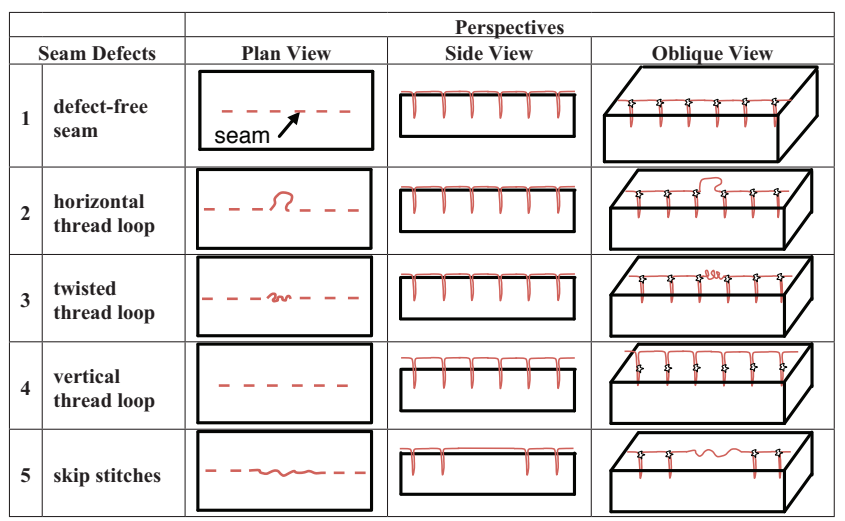

During the process images of the tufting seam are generated and analysed for seam defects by a tailor made algorithm. The development of the algorithm was carried out in three steps:
1) feature extraction out of the image
2) data processing
3) data analysis

\subsection{Feature Extraction}

First, the data to be analysed must be obtained by taking an image of a defective seam. An exemplary image of defective seam with a horizontal thread loop is illustrated in Figure 3.

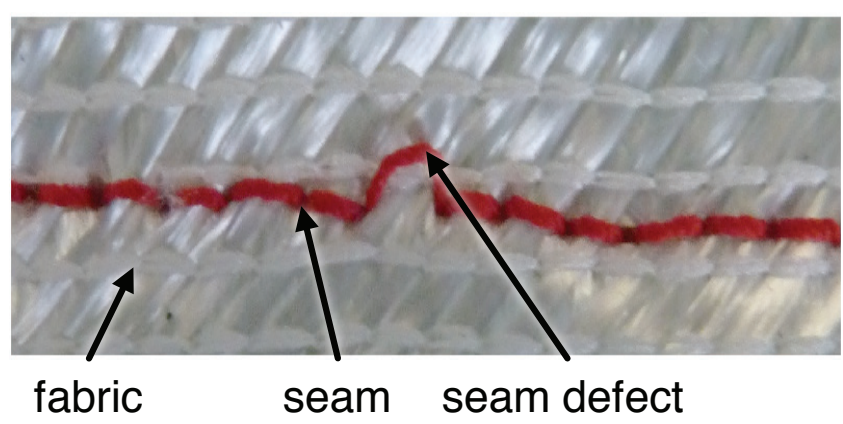

Figure 3. Image of a defective seam with a horizontal thread loop

As a next step, the relevant information contained in the image has to be extracted. The feature to be analysed in this case is the colour of the thread and fabric. Any colour can be represented by combining the intensity of three primary colours, e.g. red, green and blue. In a simulation program, the individual colour intensities of an image can be read and edited. If the colour of the thread is different than that of the sewing material, it is reflected in the colour coding. It is necessary to invoke that intensity as a decision criterion in which the yarn from fabric differs most clearly.

If, as examined in this example, a red thread is tufted on silver fabric a clear difference in the intensities of green will be measurable. The thread itself has a very low intensity compared to the background. Using a threshold value for the green intensity, the image can be decomposed into two sections. All pixels whose intensities are lower than the defined threshold will be counted as a thread. All pixels with a higher intensity will be interpreted as a fabric. All pixels that are defined as thread can be displayed in black in a new image. All other pixels are considered to be sewn and are displayed in white. The results of the image analysis are shown in Figure 4.

The extracted image only consists two colours, each representing the fabric or seam. With the feature extraction out of the original image, the first step of the algorithm ends.

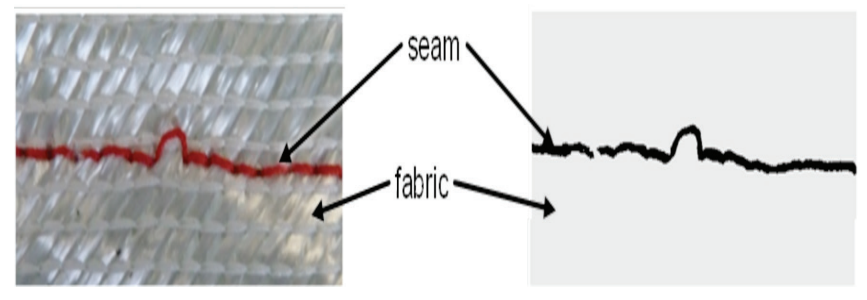

Figure 4. Decomposition of the original image (left) into the two components "thread" and "fabric" (right 


\subsection{Data Processing}

The next step is the generation and processing of the data out of the created image. Therefor a coordinate system is introduced, in which the coordinates of each image pixel can be determined. In order to detect a seam defect, an ideal seam contour must be given. Since different seams can differ in orientation or position, the predetermined ideal seam contour is to be individually adapted to the investigated seam.

The identification of the intended seam geometry within the seam defect detection software is done by a regression analysis of the detected seam progression. This approach makes the developed system flexible for varying seam geometries.

By using regression analysis of the $\mathrm{x}$ and $\mathrm{y}$ values of the stitching points, the ideal seam course can be approximated. Therefor a curve is ideally adapted to the given data points. Curves seams can't be described adequately by a 1 st order polynomial. However, straight seam pieces can also be described by a 2 nd degree polynomial. This approximation is not as accurate compared to the use of a polynomial of $1 \mathrm{st}$ order (see Figure 5), but the 2nd degree polynomial can also be used to analyse curved seams.

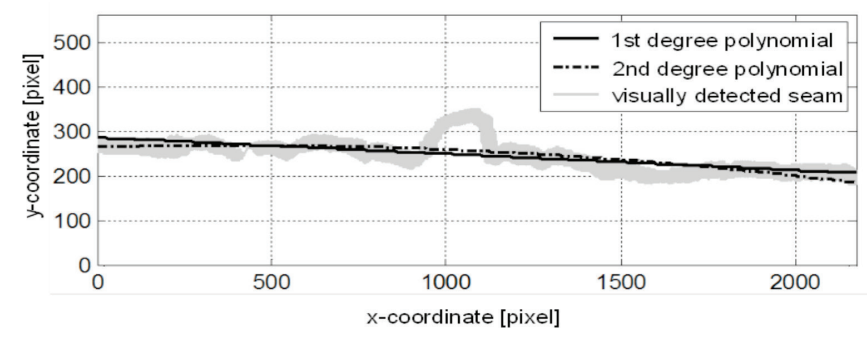

Figure 5. Comparison of approaches to adapt a straight seam by using a 1st degree polynomial and a 2nd degree polynomial

In the light of the above, a 2nd degree polynomial is used for approximating straight and curved seam sections.

\subsection{Data Analysis}

For detecting a seam defect only the outer contours of the seam and its distance from the ideal desired contour are relevant. A seam defect is deemed to exist if the distance exceeds a defined threshold. In addition, a maximum and minimum range is specified. These defect tolerance limits have a constant distance from the ideal seam contour. At those points where the seam exceeds one of these tolerance limits, a seam defect will be detected (Figure 6).
The sensitivity of the seam defect detection, which defines the minimal deviation that triggers defect detection, can be adjusted parametrically to the particular application. In addition the optical imaging can be adjusted to changes in the lighting conditions. The thread tension is being continuously measured by a sensor in the thread feeding system.
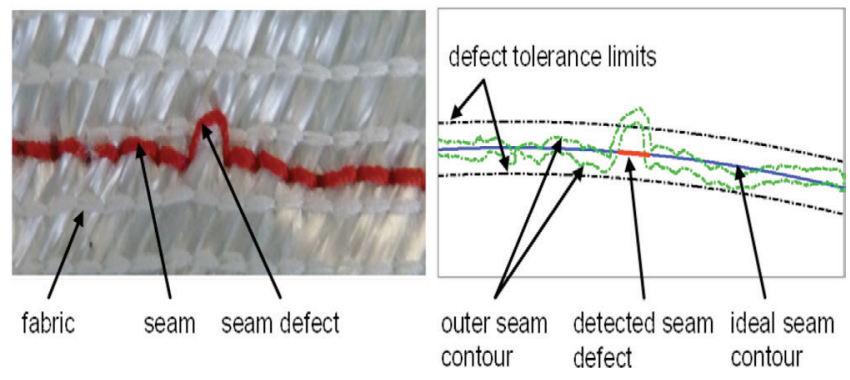

Figure 6. Depiction of automatic and visual seam defect detection: image of seam (left); detection of seam defect (right).

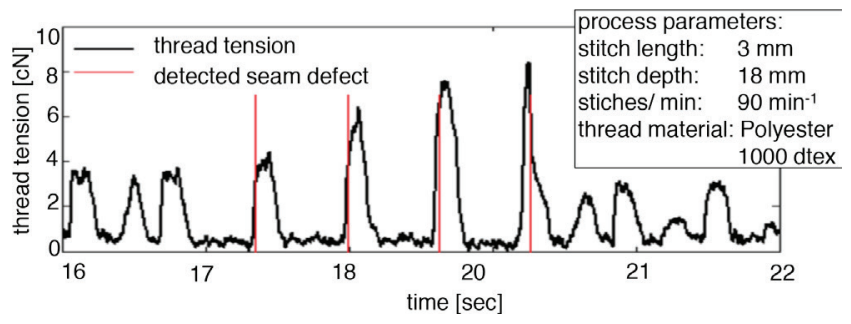

Figure 7. Thread tension over time with points in time of seam defect detection

\section{RESULTS}

The developed quality management solution is capable of recognising tufting seams and identifying seam defects. Furthermore the thread tension can be measured. Through the use of this developed system the following assessments can be executed:

- Quantification of seam defects per seam length,

- Identification of correlation between a seam defect and thread tension

- Determination of process capability

- Determination of the seam's remaining load bearing capacity

An exemplary report is shown in Figure 7. The results of thread tension measuring and optical seam defect detection are displayed automatically in a single diagram. The diagram shows the thread tension over time and in addition marks the points in time in which it detected seam defects. 


\section{CONCLUSION}

The developed inline quality measurement system is capable of detecting seam defects during the tufting process. The ability to measure in real time provides capabilities of correlating thread tension to seam defects. Optimal process parameters can be derived from these results. By means of those results the thread tension in the thread feeding system can be varied for particular cases of application to optimise the seam intrusion. Consequently the developed system yields a huge contribution to ensure a high seam quality in the tufting process.

\section{REFERENCES}

[1] AVK - Industrievereinigung verstärkte Kunststoffe e.V.: Composites - Marktbericht: Marktentwicklungen, Herausforderungen und Chancen, 2010
[2] Ehrenstein, G.W.: Faserverbund-Kunststoffe. Werkstoffe - Verarbeitung - Eigenschaften, 2. Aufl.München, Wien: Carl Hanser Verlag, 2006

[3] Frauenhofer, M.; Dilger, K.; Böhm, S.; Ströhlein, T.: Induction technique in manufacturing preforms, Mechanics of Composite Materials, Vol. 44, No. 5, 2008

[4] Cetin M.; Klingele J.; Wellekötter J.; Samorey, T.; Gries T.: Innovative Use of Expanded Polystyrene (EPS) For Textile Preforming, 1st Joint Turkey-Japan Workshop on Polymeric Composite Materials, Sabanc1 University, Istanbul, Türkei, 2014

[5] Cetin, M.; Hinck, T.; Pohlmann E.-M.; Gries, T.: Tufting process for preform fixation on foams for safe handling operations, XIII. International Izmir Textile and Apparel Symposium, Belek, Turkey, 2014. 